\title{
The Universality of Asymmetric Division
}

\author{
Matilde Canelles* \\ Instituto de Parasitologia y Biomedicina, CSIC, P. T. Ciencias de la Salud, 18100 Granada, Spain
}

Asymmetric division, a process by which stem cells divide to generate the diversity of cell types that populate adult organisms, has been extensively studied in the last decade. This has led to many exciting discoveries that help us understand how this complicated process is orchestrated.

In 1996, Zhong [1] first described this phenomenon in the mammalian neural system: stem cells segregate the fate determinant Numb asymmetrically, thus generating daughter cells with different doses of Numb and different fates. Later, it has been established that one of them usually terminally differentiates, while the other continues proliferating and retains stem cell properties. The ratio between symmetric and asymmetric division is, therefore, a crucial means to maintain a balance between the number of precursors and differentiated cells at each developmental stage. Asymmetric division has been found in virtually all developing systems where stem cells need to simultaneously proliferate and generate differentiated cells: brain, skin, gut, mammary gland, hematopoiesis of mammals (see [2] for a comprehensive review), also in plants [3] and algae [4]. This phenomenon is so ubiquitous that the focus of current research has moved from describing its existence in a certain system to establishing its still enigmatic mechanism; the discovery of links to cancer in Drosophila and hematopoiesis [5] has added momentum to an already very dynamic research area.

The immune system would seem an obvious candidate to present asymmetric division. Precursors undergo several stages that clearly fit the pattern of simultaneous proliferation and differentiation mentioned above. However, in this system, both the existence of asymmetric division and the function of Numb still remain highly controversial. Are there any biological reasons to assume that the immune system is anomalous in this respect? None has been advanced, to the best of our knowledge; the exceptionality lays, perhaps, in the approach by which asymmetric division has been studied in immunology.

Investigations on asymmetric division in other tissues normally have followed a certain and well established logical order. First, the phenomenon is extensively visualized and analyzed by microscopy. Secondly, hypotheses on its functioning and possible mechanisms are put forward, as varied and exhaustive as possible, in the spirit of the "Strong Inference" proposed by Platt [6]. Finally, knockout studies look for decisive signs in the mutant animals, based on the crucial knowledge acquired at previous stages, and pruning the hypothesis tree until a clear-cut result is reached. In these studies, the role of Numb in asymmetric division has never been questioned, since Numb itself is the main marker of this phenomenon.

Therefore, in order to properly study asymmetric division in the thymus, the logical order would have been to first establish whether immature thymocytes segregate Numb asymmetrically. Later, hypotheses on what might be the mechanism of asymmetric division in the thymus should have been developed. Only afterwards, knockout mice should have been engineered. If this sequence had been followed, one of the obvious hypotheses would have been that alterations in Numb function should affect the decision of early thymocytes between differentiation and proliferation, as has been shown in neural precursors
[7]. Given that thymocytes undergo a very early proliferation burst and do not proliferate further before exiting the thymus, this early proliferation burst should have been the focus of any knockout study on asymmetric division in the thymus. Following this reasoning, the most obvious effect of manipulating thymocyte asymmetric division would be an alteration of early thymocyte development, resulting in proliferative abnormalities and a difference in the total number of thymocytes. Obviously, this should have been examined thoroughly by knockout studies.

Unfortunately, investigations on thymocyte asymmetric division have developed in almost the inverse order. The first study published on this subject went straight to the creation of transgenic mice expressing one of the four isoforms of Numb [8]. The authors claimed that no obvious effect on thymic development was observed, however neither early thymocyte development, thymus size or thymocyte proliferation were examined. The same can be said about a Numb conditional knockout study that followed [9]. A second conditional knockout study was published where the authors tried to ablate both Numb and its homologue Numblike [10]. Here, the authors claimed that no effect was observed on early thymocyte development. However, when one examines the data, there is an intriguing, but very clear, developmental block at the double negative thymocyte stage, which would be consistent with a mild effect on asymmetric division (see Fig. $4 \mathrm{C}$ in [10]). It is known that as little as $5 \%$ of Numb or Numblike in precursors is enough to sustain normal development [11]. This fact, together with accumulating evidence that conditional knockouts have been misleading in many immunological studies [12] makes one wonder whether trace amounts of Numb and/or Numblike in the mentioned double knockout mice may have resulted in a mild phenotype. This phenotype may have been overlooked by the authors, precisely because of the lack of previous studies where asymmetric division had been visualized and analyzed in the thymus. And so, although these three first studies on the role of Numb in the thymus were hardly conclusive, they firmly set the mind of most immunologists against the idea of asymmetric division (even before the presence of asymmetric division itself had been examined in the thymus!).

Consequently, further published data on asymmetric division in both the thymus and peripheral lymphocytes, obtained using the more logical approach of examining in the first place asymmetric segregation of Numb and other cell fate determinants $[13,14]$, have been received with skepticism, since these newer data apparently "contradict"

*Corresponding author: Matilde Canelles, Instituto de Parasitologia y Biomedicina, CSIC, P. T. Ciencias de la Salud, 18100 Granada, Spain, Tel: 34958181660; Fax: 34-958181632;; E-mail: mcanelles@ipb.csic.es

Received May 10, 2011; Accepted May 11, 2011; Published November 02, 2011

Citation: Canelles M (2011) The Universality of Asymmetric Division. J Stem Cell Res Ther 1:e103. doi:10.4172/2157-7633.1000e103

Copyright: @ 2011 Canelles M. This is an open-access article distributed under the terms of the Creative Commons Attribution License, which permits unrestricted use, distribution, and reproduction in any medium, provided the original author and source are credited. 
previous knockout studies. However, this is not true; the faulty logic here lies in attributing to the knockout studies conclusions that they could never reach by their very design.

It, therefore, seems unlikely that the immune system is an exception in the universality of asymmetric division. Future, carefully designed systematic studies will hopefully soon clarify this question. It would be a sad outcome if immunology, which has often blazed new paths in the understanding of living systems, were to be left behind in the race to understand how asymmetric division works to maintain cell diversity and prevent malignant proliferation. In this context, it is important to stress the importance of classical, descriptive studies to map out the "hypothesis tree" and select the crucial experiments that need to be performed by knockout studies. In the extremely competitive field of Immunology there is a clear temptation, from both scientists and editors, to favor shortcuts. But this often leads to scientific "tunnel vision", disregarding much better alternative explanations that are never tested because lengthy and expensive knockout studies do not have a proper theoretical base on which to stand. Or, in other words: the surest way to move slowly is going in the wrong direction.

\section{Acknowledgement}

This work was supported by grant BFU2010-21634 from the Spanish Ministry of Science and Innovation and by FEDER funds from the EU.

\section{References}

1. Zhong W, Feder JN, Jiang MM, Jan LY, Jan YN (1996) Asymmetric localization of a mammalian numb homolog during mouse cortical neurogenesis. Neuron 17: 43-53.

2. Knoblich JA (2008) Mechanisms of asymmetric stem cell division. Cell 132: 583-597.

3. Paciorek T, Bergmann DC (2010) The secret to life is being different: asymmetric divisions in plant development. Curr Opin Plant Biol 13: 661-669.
4. De Smet I, Beeckman T (2011) Asymmetric cell division in land plants and algae: the driving force for differentiation. Nat Rev Mol Cell Biol 12: 177-188.

5. Knoblich JA (2010) Asymmetric cell division: recent developments and their implications for tumour biology. Nat Rev Mol Cell Biol 11: 849-860.

6. Platt JR (1964) Strong Inference: Certain systematic methods of scientific thinking may produce much more rapid progress than others. Science 146 : 347-353.

7. Petersen PH, Zou K, Hwang JK, Jan YN, Zhong W (2002) Progenitor cell maintenance requires numb and numblike during mouse neurogenesis. Nature 419: 929-934.

8. French MB, Koch U, Shaye RE, McGill MA, Dho SE, et al. (2002) Transgenic expression of numb inhibits notch signaling in immature thymocytes but does not alter T cell fate specification. J Immunol 168: 3173-3180.

9. Anderson AC, Kitchens EA, Chan SW, St Hill C, Jan YN, et al. (2005) The Notch regulator Numb links the Notch and TCR signaling pathways. J Immunol 174: 890-897.

10. Wilson A, Ardiet DL, Saner C, Vilain N, Beermann F, et al. (2007) Norma hemopoiesis and lymphopoiesis in the combined absence of numb and numblike. J Immunol 178: 6746-6751.

11. Petersen PH, Tang H, Zou K, Zhong W (2006) The enigma of the numb-Notch relationship during mammalian embryogenesis. Dev Neurosci 28: 156-168.

12. Saveliev A, Tybulewicz VL (2009) Lymphocyte signaling: beyond knockouts. Nat Immunol 10: 361-364.

13. Aguado R, Martin-Blanco N, Caraballo M, Canelles M (2010) The endocytic adaptor Numb regulates thymus size by modulating pre-TCR signaling during asymmetric division. Blood 116: 1705-1714

14. Chang JT, Palanivel VR, Kinjyo I, Schambach F, Intlekofer AM, et al. (2007) Asymmetric $T$ lymphocyte division in the initiation of adaptive immune responses. Science 315: 1687-1691. 